\title{
An Analysis of the Economic Effects for the LBS-related Industry in Korea
}

\author{
Woo-Soo Jeong ${ }^{1}$, Seung-Woan $\mathrm{Chai}^{2}$ and Kyoungsik Min ${ }^{3 *}$ \\ ${ }^{1}$ Korea Association for ICT Promotion, Seoul, Korea \\ ${ }^{2}$ Korea Internet \& Security Agency, Seoul, Korea \\ ${ }^{3}$ Korea Internet \& Security Agency, Seoul, Korea \\ E-mail: kyoungsik@kisa.or.kr (Corresponding author)
}

\begin{abstract}
This study reclassifies sub-sectors of the LBS related industry based on the definition of product and services defined above, and it uses the RAS technique to broaden a scope of an input-output table to include the LBS related industry with purpose of analyzing economic effects industry will encounter during 2017 2020. Results show that investment in the LBS related industry during 2017-2020 induces total economic outputs to KRW 2,057.7 billion and is expected to employ annually 4,567 workforce.
\end{abstract}

Keywords: LBS, Input-output table, economic effect

\section{Introduction}

A series of breakthroughs in digital information technology have created infrastructure that can digitize all sorts of information including data, audio and video, multimedia, and so forth and drastic increase in computing power through more compact and multifunctional computers has enabled large throughput of information processing at low cost. In addition, enterprise Internet environment is expanding its reach as epoch-making developments in ICT and system performance further advance digital revolution [1]. And ICT is adding new services that can help us build better environment for our life by measuring and collecting information on individuals and/or mobile objects. Hence, it becomes necessary to define industrial classification for LBS (Location-Based Service)related industries and perform relevant quantitative analysis in a bid to build a new and desirable market environment and pave way for new service offerings.

With the much-talked about attempt of Google to take digital map data of Korea out of its national border, geo-information-based service industry has come under the spotlight. Against the background, LBS-related industry is drawing attention in a variety of sectors and expectations are rising that the industry can drive the national economic growth in the future.

The purpose of this Study is to reclassify industries to conceptualize and analyze LBSrelated industries and examine economic spill-over effects of domestic investment in such industries through inter-industry analysis.

\section{LBS Industry}

\section{2..1 Concept of LBS Industry}

LBS refers to all sorts of services related to the collection, use, and delivery of "location information." Methods to measure location information is measured are divided into

Received (June 13, 2017), Review Result (August 5, 2017), Accepted (September 20, 2017)

* Corresponding Author 
network-based one, satellite signal-based one, Wi-Fi signal-based one, and hybrid positioning-based one, and so forth [2].

Table 1. Methods of Measure for LBS

\begin{tabular}{|c|c|}
\hline & Description \\
\hline \hline Network-based & $\begin{array}{r}\text { Compute location by measuring location of mobile carrier's base station } \\
\text { (Cell-ID), distance between base station and handset, etc. }\end{array}$ \\
\hline Satellite signal-based & $\begin{array}{c}\text { Compute location by drawing upon signal received from GNSS(Global } \\
\text { Navigation Satellite System) }\end{array}$ \\
\hline Wi-Fi signal-based & $\begin{array}{c}\text { A variant of network-based method. Retrieve Wi-Fi AP (Access Point, ) } \\
\text { location and compute handset location. It is also known as WPS } \\
\text { (Wi-Fi Positioning System) }\end{array}$ \\
\hline Hybrid positioning-based & $\begin{array}{c}\text { Measure handset location by combining network-based, satellite signal- } \\
\text { based, Wi-Fi signal-based locations. It is also known as HPS } \\
\text { (Hybrid Positioning System) }\end{array}$ \\
\hline
\end{tabular}

Source: Korea Communications Commission (KCC), 2016.

LBS business is divided into location information business and location-based service business. Location information business uses positioning technology to collect location information and deliver such information to location-based service business operator whereas location-based service business uses location information received from location information business operator to deliver buddy-finding, logistics, vehicle navigation services, etc. Depending on its type, location information is divided into "personal location information" and "non-personal location information." Personal location information is personally identifiable location information, including other information that is not personally identifiable but can point to the location of specific individual if it is readily combined with other information possessed by business operator. Non-personal location information is not personally identifiable information that cannot result in identification of specific individual even in combination with other information possessed by business operator.

The range of LBS-enabled services is nearly endless, including local information service, route finding, buddy finding, child location retrieval, location-based fortune telling, location-based advertising, etc. Location-enabled services are expanding primarily on smartphones to include 'Pokemon Go' utilizing LBS and augmented reality or other services converging LBS and SNS. LBS industry watchers predict that about 7 billion GNSS (Global Navigation Satellite System) handsets will be made available by 2022, a figure as big as the global population by then. In particular, with the rise of GNSS module-embedded smartphones, LBS is expected to account for $47 \%$ of the worldwide GNSS handset revenue [3]. According to Technavio Research, the global LBS market was valued at USD8.38 billion in 2014, expected to reach USD41.46 billion by 2019 at annual average growth rate of $37.68 \%$ [4].

As LBS industry grows mostly in step with mobile Internet industry, it is expected to become an integral element of such new services as IoT and O2O. In addition, LBS will make significant contribution to protecting the life and safety of the public in emergency situations as a part of social safety network. As LBS plays an increasingly critical role in our life, privacy protection is more urgently called for in terms of personal location 
information.

\subsection{Reclassification of Industries}

The As data traffic increases rapidly in combination with rise in the penetration of smartphone and mobile device and wireless Internet expand their reach, consumeroriented mobile era is being ushered in. Expansion of app market and rise in consumer demands, consumers are no longer content with passive acceptance of service offerings. They want new services in which they can participate and communicate and need Internet environment where such services can be made readily available. LBS-related industries encompass location information business and location-based service business and they are to be classified as an industry involving the entire spectrum of collecting and serving location information based on positioning technology and delivering a variety of services enabled by location information.

To analyze economic spill-over effects of LBS-related industry, we need to define industrial classification accounting for detailed items of LBS-related industry and it is not easy to classify industrial sectors applicable to LBS industry within applicable spots of input-output table. Therefore, to define the scope and classification of LBS-related industry, this Study attempts to classify LBS-related industry by reconfiguring industrial characteristics on the basis of 384 basic industrial sectors defined by the Bank of Korea. This Study reclassifies LBS-related industries into 12 industries in reference to the basic sectors (384) defined in the input-output table. For reclassification, 2013 input-output table published in 2015 which is the latest input-output table published by the Bank of Korea is used.

The classification system is configured to reclassify industries with focus on relations to LBS-related industry in order to facilitate its application to lower-tier industries and expedite classification of applicable detailed services. As such a classification system is suitable for analyzing inter-relations between LBS-related industry and other industries, it is deemed to be suitable for studying LBS-related industry in depth. Specifically speaking, LBS-related industry encompasses mobile phone, other wireless communications equipment and broadcasting equipment, measurement and analytics instruments, automatic operation and control devices, communications facilities, wireless communications service, other electric communications service, information service, software development and distribution, computer management service, other professional services, other business support services. This classification system based on the aforementioned basic sectors not only facilitates industrial classification but also expedites the analysis of detailed service classification pursuant to purpose. In the LBSrelated industry classification, industries that do not correspond to the definition of LBSrelated industry are defined as other industries which correspond to 11 industrial categories. Therefore, other industries are classified as agriculture, forestry and fisheries/mining, electric power/gas/water/recycling, construction, wholesale and retail/restaurant/lodging, transportation, banking/insurance/real estate and business service, public administration/national defense, education/healthcare/social welfare service, miscellaneous industry, non-ICT manufacturing, ICT industry (other related industries). This industrial classification is effective in supporting inter-industrial relations analysis and thereby enabling the analysis of virtuous cycle involving LBS-related industry and other industries.

\subsection{2020 Investment Plan for LBS-related Industry}

Business investment plans for LBS-related industry is estimated to be worth 1.12 trillion won in total from 2017 to 2020. This figure is derived from the market outlook data based on the 2015 LBS Industry Survey published by the Korea Internet \& Security Agency (2016) and estimated on the assumption that the annual average investment by the 
government and the private sector will be approximately 280 billion won from 2017 to 2020. (See Table 2)

Table 2. LBS Related Industry Annual Investment Plan (Unit: KRW 100 million)

\begin{tabular}{|c|c|c|c|c|c|}
\hline Year & 2017 & 2018 & 2019 & 2020 & Total \\
\hline Investment & $2,800.0$ & $2,800.0$ & $2,800.0$ & $2,800.0$ & $11,200.0$ \\
\hline
\end{tabular}

\section{Analysis Model}

\subsection{Input-Output Model}

The Input-output table is used in analyzing Economic effects of LBS-related industry on production, value addition, employment, etc. in the context of national economy. The input-output table is represented as Matrix (1) which is resolved against $X$ to produce the following input-output analysis model:

$$
\begin{gathered}
A X+Y-M=X \ldots . \\
X-A X=Y-M, \\
(I-A) X=Y-M, \\
X=(I-A)^{-1}(Y-M) \\
\Delta X=(I-A)^{-1} \Delta K \ldots \ldots .
\end{gathered}
$$

Where, $\mathrm{A}$ is input coefficient matrix, $\mathrm{X}$ total output vector, $\mathrm{Y}$ end demand vector, $\mathrm{M}$ revenue vector, and $\mathrm{K}$ investment. In Equation (2), I refers to unit matrix and $(I-A)^{-1}$ Leontief inverse matrix. As derived from Equation (3), Leontief inverse matrix can be used in identifying the effect of change in end demand on the entire economy. Namely, spill-over effect $\Delta \mathrm{X}$ on the entire economy from medium-run financial investment $\Delta \mathrm{K}$ in relation to change in end demand can be computed by Equation (3). To estimate only spill-over effect on the production of domestic goods and services from occurrence of end demand, production inducement coefficient of $\left(I-A^{d}\right)^{-1}$ type derived from transactions table of domestic goods and services is used. Production inducement coefficient is obtained by dividing gross output by labor input for production activities of each industrial sector and it refers to labor directly spent on producing one unit.

\section{Analysis Findings \& Implications}

It was found in the analysis that the production inducement coefficient of LBS-related industry was 1.8372 , value addition inducement coefficient 0.7026 , and employment inducement coefficient 0.8872 . (See Table 3.)

Table 3. Inducement Coefficient of LBS Related Industry

\begin{tabular}{|c|c|c|c|}
\hline & Production & Value Addition & Job \\
\hline Agriculture, forestry, and fisheries/mining & 1.8644 & 0.7932 & 0.4495 \\
\hline Electric power/gas/water/recycling & 1.6193 & 0.4350 & 0.3000 \\
\hline Construction & 2.2310 & 0.7067 & 0.9909 \\
\hline Wholesale and retail/restaurant/lodging/transportation & 1.8862 & 0.7528 & 1.1054 \\
\hline Banking and insurance/real estate and business service & 1.6235 & 0.8796 & 0.9905 \\
\hline Public administration/national defense & 1.3886 & 0.9175 & 1.0513 \\
\hline
\end{tabular}




\begin{tabular}{|c|c|c|c|}
\hline Education/healthcare/social welfare service & 1.6668 & 0.8440 & 1.5432 \\
\hline Culture and other services & 1.9102 & 0.7872 & 1.4379 \\
\hline Miscellaneous & 2.1308 & 0.7463 & 1.2538 \\
\hline Non-ICT manufacturing & 2.1131 & 0.5228 & 0.5147 \\
\hline Other related industries (ICT) & 1.8611 & 0.5485 & 0.4388 \\
\hline LBS-related industry (ICT) & 1.8372 & 0.7026 & 0.8872 \\
\hline
\end{tabular}

Production inducement effect, value addition inducement effect, and employment inducement effect as expected benefits of investment in LBS-related industry from 2017 to 2020 are as shown in Table 4 .

Table 4. Economic Effects of LBS Related Industry

\begin{tabular}{|c|c|c|c|c|c|}
\hline Classification & 2017 & 2018 & 2019 & 2020 & Total \\
\hline Production inducement effect (in 100 million won) & 5,144 & 5,144 & $5,144.2$ & $5,144.2$ & $20,576.7$ \\
\hline Value addition inducement effect (in 100 million won) & 3,614 & 3,614 & $3,614.4$ & $3,614.4$ & $14,457.6$ \\
\hline Employment inducement effect (in 100 million won) & 4,564 & 4,564 & $4,564.0$ & $4,564.0$ & $18,256.0$ \\
\hline
\end{tabular}

Total production inducement as economic spill-over effect of LBS-related industry is estimated to reach approximately 2.577 trillion won from 2017 to 2020, which indicates that the spill-over effect of investment in LBS-related industry will reach approximately 2.577 trillion won or 1.84 times investment amount. Value addition inducement effect is valued at approximately 1.4458 trillion won. Employment inducement is estimated to be equal to about 4,567 jobs on annual average from 2017 to 2020, assuming that the employment inducement coefficient of LBS-related industry is 0.8872 job per 100 million won. This, in turn, indicates that through spill-over effect, LBS-related industry will create about 18,256 jobs both directly and indirectly by 2020

Table 4. Comparison of Employment inducement Coefficient

\begin{tabular}{|c|c|c|}
\hline \multicolumn{2}{|c|}{ Classification } & $\begin{array}{c}\text { Employment inducement } \\
\text { coefficient }\end{array}$ \\
\hline \multirow{2}{*}{$\begin{array}{c}\text { Broadcasting/communications } \\
\text { convergence platform implementation }\end{array}$} & Implementation & 0.69 \\
\cline { 2 - 3 } BcN industry & Utilization & 0.47 \\
\cline { 2 - 3 } & BcN equipment & 0.61 \\
\hline \multirow{2}{*}{ Healthcare ICT } & BcN service & 0.72 \\
\cline { 2 - 3 } & Healthcare equipment & 0.46 \\
\hline \multirow{2}{*}{ Smart network } & Healthcare service & 0.13 \\
\hline Mobile Internet & Implementation & 0.57 \\
\hline Network & Utilization & 0.59 \\
\hline Information security & & 0.37 \\
\hline LBS-related industries & & 0.78 \\
\hline
\end{tabular}

Source: Woo-soo Chung \& Seung-taek Lee, (2009) [5], Hyung-taek Ahn, et. al.,(2005) [6], Woo-soo Chung (2007) [7], Woo-soo Chung \& Sah-hyuk Kim(2011) [8], Myeong-hwan Im \& Sang-seop Cho(2004) [9], Woo-soo Chung (2012) [10] 
Implications identified in this Study are as follows: Firstly, the employment inducement coefficient of LBS-related industry analyzed herein is higher than other ICTrelated industries at 0.8872 . As its employment inducement coefficient is higher than other ICT-related industries, investment in LBS-related industries is expected to result in more job creation. It is expected that future growth of LBS-related industries will make significant contribution to job creation. (See Table 5.);

Secondly, LBS-related industries deserve to be classified as future-oriented ICTenabled industries and new growth drivers with high potential for value addition. In addition, they are expected to stimulate investment and penetration as new services based on creative ideas employing underlying technologies can be developed. Therefore, division of responsibilities between government and private sector and creation of program governance structure will play a critical role in shaping the outcome of relevant programs; and

Thirdly, conditions conducive to the promotion of new service offerings need to be put in place. Success of new industry resulting from new investment initiatives depends on availability of stable market platform and popularization of applicable services. It is necessary to facilitate a paradigm shift from supply-oriented system underpinned by conventional technologies to demand-oriented market environment. To deploy stable market environment, it is recommended that promising services be identified, selected, and focused on to provide input for implementation of service promotion support system.

\section{References}

[1] W.-S. Chung, K.-S.Min and S.-W. Chai, "An Analysis of Economic Effects of Information Security Industry", Journal of Korea Institute of Information Security \& Cryptology, vol. 24, no. 2, (2014), pp. 299-310.

[2] Korea Communications Commission, "Location Information Use Promotion Plan", (2016).

[3] GSA, GNSS Market Report, no. 3, (2013).

[4] Technavio Research, Global LBS Market 2015-2019, (2015).

[5] W.-S. Chung and S.-T. Lee, "An Analysis of Economic Effects of Broadcasting \& Communications Convergence Public Service Platform Implementation Program", Journal of Korea Institute of Communication Sciences, vol. 34, no. 09-07, (2009).

[6] H.-T. Ahn, W.-S. Chung, S.-Y. Nam, "A Study of Economic Effects of BcN Deployment Program on National Economy”, National Information Society Agency, (2005).

[7] W.-S. Chung, K.-Y. Ji, S.-Y. Kim and Y. Kim, "A Study of Knock-on Effects of Healthcare ICT Industry on National Economy", Journal of Korean Society of Medical Informatics, vol. 13, no. 4, (2007), pp. 321-333.

[8] W.-S. Chung and S.-H. Kim, "An Analysis of Economic Effects of Smart Network Deployment Program”, Journal of Korean Society for Internet Information, vol. 12, no. 4, (2011).

[9] M.-H. Im and S.-S. Cho, "An Analysis of Economic Effects of Mobile Internet on National Economy", Telecommunications Review, vol. 14, no. 1, (2004).

[10] W.-S. Chung, "An Analysis of Economic Viability of ICT Infrastructure for Promoting Advancement of ICT Networks", National Information Society Agency, (2012). 